\title{
TODAS AS PALAVRAS MORAM NO RELOGIO
}

\author{
Tradução de um ensaio de Shûji \\ Terayama
}

\section{Geny Wakisaka}

Todos os integrantes do circo, que vira quando menino, tinham cada qual o seu relógio. Cheguei a perguntar a uma artista da "troupe" - "Se cada qual possui o seu relógio não dá briga?" Com uma fisionomia inquiridora, ar estranho, ela retrucou - "Por que?" Disse eu: "Porque não dá para saber em que hora acreditar." Entretanto, a artista me disse que nenhuma hora conflita com a outra. Ela quis dizer que cada hora possui a sua órbita e nenhuma se choca com outra.

Nessa noite, quando voltei à casa pedi à minha mãe que comprasse um relógio de pulso. E minha mãe, apontando para o único relógio da casa, um pêndulo, colado à parede: - "A melhor coisa para a hora é deixá-la encerrada dentro desse relógio grande, pendurada na parede. Todos podem ter a mesma hora e todos são felizes." E com olhar de censura fitou-me e disse: - "E despropósito querer colocar a hora dentro de um relógio de pulso e levá-la para fora de casa."

Caminhando na paisagem hibernal

Sob o braço, toca de repente

$O$ relógio de pêndulo a ser vendido

(Morte na Paisagem Rural)

Quando o "relógio de pêndulo", à parede, é o totem da "casa", o "relógio de pulso" é a alegoria do desejo de escape da "casa" 
A hora do relógio de pulso - apreendê-la como irrealidade dentro do cotidiano ou, aprofundando o cotidiano, considerá-la como reflexo interior da unidade pulverizada - fica a critério de cada um, mas para o menino que eu era, o relógio de pulso foi apreendido como sinônimo de viagem corporificada na "troupe" do circo. In fine, relógio de pèndulo à parede = casa, se apoia no ponteiro horário, e a "troupe" do circo dá volta com o ponteiro de segundo no interior da unidade e volve ao ponto original. Ambos me alcançam como zoadas de uma longíqua festa de palhaços do sistema sexagesimal. Isto pode ser que se tenha constituido no cerne da minha literatura, do cinema e do teatro.

Quando da minha saída da casa, amarrando o relógio de pêndulo com grossas cordas de cânhamo despedi-me da "hora una",

Pedinte andarilho que toca os sinos aos céus

$\mathrm{Na}$ terra prostitu ta-mãe

Papoulas de vermelho sangue

Florecem no inferno da casa

Montanhas de pavor do relógio de pêndulo

Tenho sido o filho ingrato

(Morte na Paisagem Rural)

Ouvindo o toque do relógio de pêndulo da "casa" a cada hora, o menino que era eu, de certa feita imaginou um relógio que "mentia"

Que tocava sete quando era uma hora; um relógio que batia doze quando eram cinco horas. Um relógio imaginário que invertia o dia e a noite. Ele, muitas vezes, com muito ódio, soltava toques que lembravam o inferno. Batidas de cinco horas após uma hora, e em seguida seis horas, quatro horas.

À noite alta, quando eu estava a ler um romance policial de Chesterton, bate meia noite. Cerca de uma hora depois bate novamente 0 toque da meia noite. $E$ mais uma hora depois, outro toque da meia noite. A leitura do romance adiantou um bocado; e a sensação de medo que me possui pela repetição da meia noite. Ou, ao começar a tocar meia noite, não mais pára de tocar; treze, quatorze, num crescendo; cem, mil, dez mil; tocando sempre - e a sensação de que os homens vão envelhecendo, contando esses toques...

$\mathrm{Na}$ caixa de costura

$A$ agulha envelhece 
Mas ela já não cose

$O$ liame entre mim e a mäe.

(Morte na Paisagem Rural)

E por falar nisso, uma vez escrevi a história de um homem com "cronofobia"

Ao homem que tentara suicidar-se recentemente perguntei as razões. Respondeu-me que tinha medo do relógio. Do cadáver da velha mãe que se enforcara no velho relógio de parede; o pêndulo à mercê do vento, a marcar os meus dias. Simplesmente a insegurança. Todavia, pelo "tempo" determinado por outrem, julgar o meu dia a dia é imperdoável. Tentei-me tornar-me o próprio relógio.

Riscar um círculo no solo. E no centro de pé, fazer com que o sol crie a minha sombra. Fazê-la ponteiro, e me tornar o núcleo do relógio humano. Não haverá maior precisão. Dia após dia, apenas aguardar o tempo e passar o tempo sem nada fazer. A felicidade. $E$ assim disse o homem que nunca mais se atrasou, em relação ao tempo. A partir do dia da morte, marcando o tempo inverso, o relógio que nunca chega ao "presente" Homem - não precisa cantar como cuco.

(O inferno)

0 "tempo" que se dispersa juntamente com o som do relógio, encerrando no seu bojo a acidentalidade passível de reformulação, sempre provoca o segundo acontecimento. "O corpo humano é uma máquina que dá corda a si mesma sendo exemplo vivo do movimento perpétuo. O corpo humano é um relógio, por sinal um enorme relógio, construído com extrema habilidade e refinamento." - disse-o o médico Julien Offroy de la Metrie ("L'homme machine"), um dos filósofos mais radicais do materialismo francês do século XVIII. Entretanto ao escrever sobre o homem com "cronofobia" talvez tenha tentado também a transformação em relógio.

O tempo do relógio de pulso, a despeito de parecer um tempo próprio, na verdade não passa de um complemento da hora histórica. Se se tentar realmente fugir do "tempo" deve se transformar em relógio, podendo dizer que não há outra alternativa senão continuar eter- 
namente a considerar que - "não é história apenas aquilo que é registrado, mas também muito do que não foi registrado faz parte da história."

Há a seguinte passagem no "Père Zaccarius" de Verne que descreve o homem possuído pelo relógio:

- E estranho que a máquina se mova sozinha e meça o tempo. Devia ficar apenas com o relógio solar.

- Relógio solar! Oh, que medo. E uma invenção de Caim. 


\section{NOTA DA TRA.DUTORA}

Há tempo traduzimos este ensaio de Shûji Terayama, poeta, teatrólogo, ligado também ao murido do cinema e da telenovela japonesa.

Terayama faleceu em 4 de março de 1983, aos 47 anos de idade, vencido pela nefrose que o acometera desde 1954. Em novembro de 54, recebia o Prêmio ao Principiante, oferecido anualmente pelo periódico Tanka Kenkyû (pesquisas do Tanka), ao tankaista iniciante que mais se destaca durante o ano. Terayama fez jus ao prêmio pelos seus 50 tanka (poema japonès de 31 sílabas) enviados à comemoração do "Cinqüentenário de Tchekhov" realizada no Japão. No mesmo ano, encenava a sua peça teatral Ushinawareta Ryôbun (O Espaço Perdido), para a Festa do Verde organizada na Universidade de Waseda.

Em 1957. publica o seu livro de poemas e prosas Wareni Gogatsuo (A Mimo Mês de Maio): Hadashino Koiuta (Os Cantos dos Amores Descalços), além de enviar inúmeros Tanka ao periódico Tanka Kenkyû.

Em 1958, organiza a sua primeira coletânea de Tanka, Soraniwahon (O Livro aos Céus) e se consagra um dos tankaista de vanguarda no cenário poético japonês.

Não se contentando porém com a forma fixa do estilo Tanka, procura ativamente outras formas de expressão como o teatro, o cinema, a novela de rádio e TV, o romance e os ensaios críticos, propulsionando concomitante um movimento de libertação da emotividade humana através da expressividade artística em substituição a um meramente político. Assim, em 1967 organiza com Tadanori Yokoo e outros, uma companhia teatral batizada de Tenjo Sajiki (Grupo Teatral Galeria), $\infty \mathrm{m}$ estas finalidades.

São consideradas suas obras representativas em poemas, Chito Mugui (Sangue e trigo); Den-enni Shisu (Morte na Paisagem Rural); Aa Kôya (Prados...), e o poema épico Jigokuhen (Inferno). Como peça teatral destaca-se Chiwa Tattamama Nemutte Iru $(0$ sangue adormece de pé).

O ensaio ora traduzido, Todas as Palavras Moram no Relógio, fora encontrado casualmente na revista literária Kokubungaku Kaishakuto Kanshó, de setembro de 1979, ed. Shibundó. Impressionou-nos a noção de Tempo implicada à concepção de liberação do homem, elaborado pelo autor num desespero e pessimismo, que só um poeta poderia expressar com tanto eufemismo.

Tive a felicidade de poder acrescentar à nossa tradução, algumas notas traçadas num átimo de tempo por minha orientadora Profa Drạ Aurora Fornoni Bernardini, responsável pelo curso de Teoria Literária e Literatura Comparada em Pós Graduação da USP

Consegui desta feita, graças à sua valiosa colaboração, reunir aqui, dois ensaios, o ocidental sobre o oriental, para a apreciação do nosso círculo de leitores. 


\section{NOTA INGENNUA DE UMA LEITORA OCIDENTAL}

\section{Aurora Fornoni Bernardini}

A sensação que nós ocidentais temos à transleitura de um texto japonés é imediatamente de deslumbramento.

Mesmo um texto-ensaio como este, parece-nos um poema, e que poema. Abstrato, concreto, real e irreal, denso de verdades-inverdades absolutas e eternas, que se aninham no tempo.

Aos poucos tentamos racionalizar: descobrir um sentido possivel, nas explicạ̣ōes, nas entrelinhas. Mas o que: elas são mais fugidias que o próprio texto.

Fica-nos, por momentos, a impressão de que "o menino que era" quer o relógio de pulso - para levar a hora pra fora de casa e a si próprio com ela. Quando ele sai porém, relógio de pulso e péndulo se fundem como ecos da mesma farsa do sistema horário e quem sai ganhando no fim é o péndulo que escande rumorosamente os toques inevitáveis da vida.

A casa, a mãe: tentação de atribuir-lhes a irresistibilidade do feminino, para o menino de outrora, não desconfiasse eụ que em japonês não há gênero.

A mãe que se enforca no pêndulo: o tempo que apara, inclemente, os liames.

O tempo sem tempo. A felicidade: 0 inferno.

Oxímoros se devoram um ao outro "encerrando em seu bojo a acidentalidade passivel de reformulação." Quem sabe a esperança, a provocar o acontecimento seguinte: "O corpo humano é uma máquina que dá corda a si mesma" exemplo vivo do tempo - movimento perpétuo. Ninguém escapa.

Na busca de uma alternativa, acaba por tornar-se máquina, ele próprio.

A não ser que volte ao menino que era. 